\title{
Long-term Use of Macrolides for Non-cystic Fibrosis Bronchiectasis: The Benefits and Defects
}

\section{Li-Chao Fan and Jin-Fu Xu*}

Department of Respiratory Medicine, Shanghai Pulmonary Hospital, Tongji University School of Medicine, Shanghai, China

Non-cystic fibrosis bronchiectasis is a respiratory disease characterized by persistent airway inflammation and dilation of bronchial wall driven by diverse etiology [1]. Patients with bronchiectasis suffer a lot from sputum production, recurrent exacerbations, and progressive airway destruction [2]. From 2000 to 2007, the prevalence of bronchiectasis in the United States was 1,106 cases per 100,000 people with an annual percentage increase of $8.74 \%$ [3]. The average annual hospitalization rate was 9.4 per 100,000 populations in Germany during 2005-2011, with the highest rate of 39.4 hospitalizations per 100,000 populations among men aged 75-84 years [4]

With the widely used of High-Resolution Computed Tomography (HRCT), more and more bronchiectasis can be diagnosed. Major therapy for bronchiectasis is focused on breaking the "vicious cycle" of mucus stasis, infection, inflammation, and airway destruction [5]. Mounting evidences have been shown that 14- and 15-membered ring macrolides possess immune-regulatory and anti-inflammatory functions beyond their antimicrobial effects [6]. Clinical benefits of macrolides have been observed in cystic fibrosis, diffuse panbronchiolitis and asthma patients. Reports showed that macrolides maintain therapy could reduce frequency of respiratory exacerbations, decreased 24 hour sputum volume and improved quality of life. More recently, 3 large trials have been published on the effects of macrolides in non-CF bronchiectasis.

In the EMBRACE trial, 141 patients were randomly assigned to two groups in a ratio of 1:1, receiving azithromycin $500 \mathrm{mg}$ or placebo three times a week for 6 months and observed for the next 6 months [7]. At the end of the 6-month treatment period, the azithromycin group had a $62 \%$ relative reduction in rate of exacerbations compared to placebo (rate of exacerbations: 0.59 in treatment vs. 1.57 in placebo group, rate ratio $0.38,95 \%$ CI $0.26-0.54 ; \mathrm{P}<0.0001$ ). This benefit was also observed in the 12 -month period, corresponding to a $42 \%$ relative reduction of annual rate of exacerbations with azithromycin group $(\mathrm{p}<0.0001)$. Time to a first exacerbation was greater in the anithromycin group than in the placebo group ( 239 vs. 85 days; rate ratio $0.44,95 \% \mathrm{CI}$, $0.29-0.65, \mathrm{p}<0.0001)$. In patients receiving azithromycin, decreases in postbronchodilator FVC (L) from baseline in the 6 months and 12 months were less compared with placebo group. However, there was no significantly difference in the changes of prebronchodilator and postbronchodilator FEV1 (L) between the two groups. The symptom component of the SGRQ was improvement in the azithromycin group than in the placebo group at 6 months, but no significant difference was observed in other SGRQ component scores at 6 and 12 months. Concentration of C-reactive protein, peripheral WBC, and peripheral neutrophils were favoring lower inflammation in the treatment group.

In the BAT randomized controlled trial, 43 non-CF bronchiectasis patients receiving azithromycin $250 \mathrm{mg}$ daily and 40 patients receiving placebo for 12 months [8]. At the end of the study, patients receiving azithromycin had a median number of exacerbations of 0 , (interquartile range [IQR], 0-1) compared with 2 (IQR, 1-3) in the placebo group $(\mathrm{P}<0.001)$. The difference was most impressive at 90 days (2 exacerbations in azithromycin group vs. 22 in placebo group). Patients who had at least 1 exacerbation were significant reduced in the azithromycin-treated group (hazard ratio, 0.29, 95\%CI 0.16-0.51). The percent of predicted FEV1 increased 1.03 per 3 months in azithromycin group, while decreased 0.10 per 3 months in patients receiving placebo $(\mathrm{P}=0.047)$. The changes in percent of predicted FVC were in the same direction. Quality of life measured by SGRQ and LRTI-VAS score both showed a larger decrease of the total score (indicating improvement) in azithromycin group compared with placebo at the end of treatment $(\mathrm{p}<0.05)$. There was no significant difference noted in change of CRP and $\mathrm{WBC}$ count between the two groups.

In the BLESS trial, 117 patients ( 58 placebo, 59 erythromycin) were randomized to receive either erythromycin ethylsuccinate $400 \mathrm{mg}(250$ mg erythromycin base) twice daily, or placebo for 48 weeks [9]. There was a significant reduction of protocol defined exacerbations (PDPEs) in favor of erythromycin group (1.29 in the treatment group vs. 1.97 in the placebo group; IRR, $0.57,95 \% \mathrm{CI}, 0.42-0.77, \mathrm{p}=0.003$ ). 24-hour sputum weight was significantly reduced in erythromycin group compared with placebo (median difference, $4.3 \mathrm{~g}$, IQR, 1-7.8, P=0.01). Erythromycin significantly attenuated the decline in postbronchodilator FEV1 percent predicted (change from baseline, -1.6 in erythromycin group and -4.0 in placebo group, $\mathrm{p}=0.04$ ). However, there was no significant difference observed in SGRQ scores, Leicester cough questionnaire scores, percent of sputum neutrophils, CRP or 6-minute walk test results.

Several small clinical studies evaluated the action of macrolides on patients with bronchiectasis in the last decade. Koh and his colleagues in a randomized, double-blind, placebo-controlled study with 25 children in a ratio of $1: 1$ treated with roxithromycin or placebo $(4 \mathrm{mg} / \mathrm{kg}$, b.i.d.) for 12 weeks. A significant improvement in sputum features were noted after 6 weeks of treatment in the roxithromycin group. Cymbala and his colleagues enrolling 12 patients treated with azithromycin $(500 \mathrm{mg}$ twice weekly) plus supportive therapy for 6 months [10]. This study showed significantly fewer incidences of exacerbations and reduced 24hour sputum volume. Meanwhile, patients in the azithromycin group reported increased energy and quality of life. A pilot study of 21 patients with bronchiectasis was conducted to treat with erythromycin $(500 \mathrm{mg}$ b.i.d.) for 8-week. The results showed that forced expiratory volume in one second (FEV1), forced vital capacity (FVC) and 24-h sputum volume were significantly improved at the end of study $(\mathrm{p}<0.05)$ [11] An open-label prospective study enrolling 30 patients investigated the effect of azithromycin ( $250 \mathrm{mg}$ three times per week) for three months. The results showed that sputum volume; number of exacerbations, dyspnea, and quality of life were significantly improved after therapy [12].

An important matter of concern to the widespread implementation

*Corresponding author: Jin-Fu Xu, Department of Respiratory Medicine Shanghai Pulmonary Hospital, Tongji University School of Medicine, Shanghai, China, E-mail: jfxu@ymail.com

Received November 25, 2013; Accepted November 25, 2013; Published November 28, 2013

Citation: Fan LC, Xu JF (2013) Long-term Use of Macrolides for Non-cystic Fibrosis Bronchiectasis: The Benefits and Defects. J Pulm Respir Med 3: e131. doi:10.4172/2161-105X. 1000e131

Copyright: (๑) 2013 Fan LC, et al. This is an open-access article distributed under the terms of the Creative Commons Attribution License, which permits unrestricted use, distribution, and reproduction in any medium, provided the original author and source are credited. 
Citation: Fan LC, Xu JF (2013) Long-term Use of Macrolides for Non-cystic Fibrosis Bronchiectasis: The Benefits and Defects. J Pulm Respir Med 3: e131. doi:10.4172/2161-105X.1000e131

Page 2 of 3

of long-term use macrolide is adverse effects. The main adverse events reported were nausea, vomiting, diarrhea, and abdominal pain. In the EMBRACE trial, gastrointestinal symptoms were more complained in the azithromycin group compared with placebo $(\mathrm{p}=0.005)$. In the BAT trial, diarrhea ( 9 vs. $1, \mathrm{RR}=8.36,95 \% \mathrm{CI}, 1.10-63.15$ ) and abdominal pain ( 8 vs. $1, \mathrm{RR}=7.44,95 \% \mathrm{CI}, 0.97-56.88$ ) showed high risk in patients receiving azithromycin. Other adverse effects including rash, auditive complains, itching, palpitations and headache were similar between the two groups. Ray et al. reported a small absolute increase in cardiovascular deaths during 5 days of azithromycin therapy [13]. Trials addressed this issue were rare, only the BLESS study reported that there was no evidence of macrolides caused QTc prolongation or arrhythmogenicity. However, an ECG should be performed to evaluate the QT interval and potential cardiovascular events in clinical practice.

Another critical issue limiting the use of long-term macrolides therapy is the risk of induction of resistant bacterial strains. In the BLESS trial, the proportion of macrolide resistant commensal oropharyngeal streptococci was significantly increased in erythromycin treatment (difference, $25.5 \%, \mathrm{IQR}, 15 \%$ to $33.7 \%, \mathrm{P}<0.001$ ). Likewise, azithromycin showed a high risk of macrolide resistant in the BAT trial (88\% vs. $26 \%$, $\mathrm{p}<0.001)$. Although macrolide resistance was not routinely tested in the EMBRACE trial, but $4 \%$ participants still developed macrolideresistant Streptococcus pneumoniae in the azithromycin treatment group. A trial of macrolides maintenance therapy in patients with cystic fibrosis showed that erythromycin resistance in Staphylococcus aureus increased from 6.9 to $53.8 \%$ and clarithromycin resistance in Haemophilus species from 3.7 to $37.5 \%$ [14]. Increasing attention should be paid to non-tuberculous mycobacteria (NTM) fostered by chronic use of macrolides. Experts recommend that routine screening for NTM should be considered for persons with non-CF bronchiectasis.

In conclusion, although long-term low-dose macrolides have great potential for non-CF bronchiectasis treatment, patients should be carefully evaluated during the following up treatment. A balance between clinical benefit and potential development of macrolides resistance in pathogens and adverse events should be well weighed. We recommend that patients who have had more than two exacerbations in the past year without NTM infection could be prescribed long-term macrolides therapy.

\section{Acknowledgements}

This work was supported by the National Science Foundation of China
[NSFC81170003, 81370109], Shanghai Pujiang Project [12PJD004] and Shanghai Elite Medical Talent Project [XYQ2011006].

\section{References}

1. McShane PJ, Naureckas ET, Tino G, Strek ME (2013) Non-cystic fibrosis bronchiectasis. Am J Respir Crit Care Med 188: 647-656.

2. Pasteur MC, Bilton D, Hill AT; British Thoracic Society Bronchiectasis nonCF Guideline Group (2010) British Thoracic Society guideline for non-CF bronchiectasis. Thorax 65: i1-58.

3. Seitz AE, Olivier KN, Adjemian J, Holland SM, Prevots R (2012) Trends in bronchiectasis among medicare beneficiaries in the United States, 2000 to 2007. Chest 142: 432-439.

4. Ringshausen FC, de Roux A, Pletz MW, Hämäläinen $N$, Welte $T$, et al (2013) Bronchiectasis-associated hospitalizations in Germany, 2005-2011: a population-based study of disease burden and trends. PLoS One 8: e71109.

5. Cole PJ (1986) Inflammation: a two-edged sword--the model of bronchiectasis Eur J Respir Dis Suppl 147: 6-15.

6. Bartold PM, du Bois AH, Gannon S, Haynes DR, Hirsch RS (2013) Antibacterial and immunomodulatory properties of azithromycin treatment implications for periodontitis. Inflammopharmacology 21: 321-338.

7. Wong C, Jayaram L, Karalus N, Eaton T, Tong C, et al. (2012) Azithromycin for prevention of exacerbations in non-cystic fibrosis bronchiectasis (EMBRACE) a randomised, double-blind, placebo-controlled trial. Lancet 380: 660-667.

8. Altenburg J, de Graaff CS, Stienstra Y, Sloos JH, van Haren $\mathrm{EH}$, et al. (2013) Effect of azithromycin maintenance treatment on infectious exacerbations among patients with non-cystic fibrosis bronchiectasis: the BAT randomized controlled trial. JAMA 309: 1251-1259.

9. Serisier DJ, Martin ML, McGuckin MA, Lourie R, Chen AC et al. (2013) Effect of long-term, low-dose erythromycin on pulmonary exacerbations among patients with non-cystic fibrosis bronchiectasis: the BLESS randomized controlled trial. JAMA 309: 1260-1267.

10. Cymbala AA, Edmonds LC, Bauer MA, Jederlinic PJ, May JJ, et al. (2005) The disease-modifying effects of twice-weekly oral azithromycin in patients with bronchiectasis. Treat Respir Med 4: 117-122.

11. Tsang KW, Ho PI, Chan KN, Ip MS, Lam WK, et al. (1999) A pilot study of lowdose erythromycin in bronchiectasis. Eur Respir J 13: 361-364.

12. de Diego A, Milara J, Martinez E, Palop M, León M, et al. (2013) Effects of Long-term Azithromycin Therapy on Airway Oxidative Stress Markers in Noncystic Fibrosis bronchiectasis. Respirology .

13. Ray WA, Murray KT, Hall K, Arbogast PG, Stein CM (2012) Azithromycin and the risk of cardiovascular death. N Engl J Med 366: 1881-1890.

14. Phaff SJ, Tiddens HA, Verbrugh HA, Ott A (2006) Macrolide resistance of Staphylococcus aureus and Haemophilus species associated with long-term azithromycin use in cystic fibrosis. J Antimicrob Chemother 57: 741-746. 
Citation: Fan LC, Xu JF (2013) Long-term Use of Macrolides for Non-cystic Fibrosis Bronchiectasis: The Benefits and Defects. J Pulm Respir Med 3: e131. doi:10.4172/2161-105X.1000e131

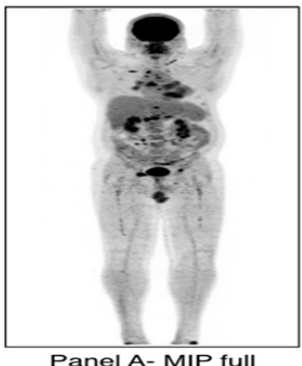

Panel A- MIP full

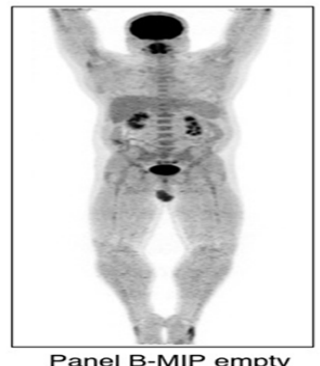

Panel B-MIP empty

FDG-PET/CT MIP (Maximum Intensity Projection) images of the same patient during initial treatment (panel A) and after changing treatment (panel B). Panel A shows intensely hypermetabolic sarcoid disease in the heart, bones and lymph nodes while the patient was on treatment with steroids. Panel B shows complete response to new treatment

Figure 1: FDG-PET/CT Imaging. 